\title{
Contaminant Tailing in Highly Heterogeneous Porous Formations: Sensitivity on Model Selection and Material Properties
}

Authors: Mahdi Maghrebi ${ }^{1 *}$, Igor Jankovic ${ }^{1}$, Gary S. Weissmann ${ }^{2}$, L. Shawn Matott ${ }^{3}$, Richelle M Allen-King ${ }^{4}$, Alan J Rabideau ${ }^{1}$

\author{
Affiliations: \\ ${ }^{1}$ Department of Civil, Structural, and Environmental Engineering, The State University of New \\ York at Buffalo \\ ${ }^{2}$ Department of Earth and Planetary Sciences, The University of New Mexico \\ ${ }^{3}$ Center for Computational Research, The State University of New York at Buffalo \\ ${ }^{4}$ Department of Geology, The State University of New York at Buffalo
}

* Contact Information of Corresponding Author:

Email: maghrebi@buffalo.edu

Tel: +1-7166454013

Fax: +1-7166453667

Keywords: Contaminant Tailing, Heterogeneous Formations, Multi-Indicator Model, TPROGS, Borden Formation 


\begin{abstract}
:
Coupled impacts of slow advection, diffusion and sorption were investigated using two heterogeneity models that differ in structure and in the mathematical framework that was used to simulate flow and transport and to quantify contaminant tailing. Both models were built using data from a highly heterogeneous exposure of the Borden Aquifer at a site located $2 \mathrm{~km}$ northwest of the Stanford-Waterloo experimental site at Canadian Forces Base Borden, Ontario, Canada. The inclusions-based model used a simplified representation of the different materials found at the site, while the second model was based on transitional probability geostatistics of the formation. These two models were used to investigate sensitivity of contaminant tailing on model selection and on geometric and material properties. While simulations were based on data collected at Borden, models were exercised beyond the geometric and material properties that characterize the site. Various realizations have identified very low conductive silty clay, found at volume fraction of $23.4 \%$, as the material with dominant influence on tailing, and vertical diffusion in and out of low conductive units, affected by sorption, as the dominant transport mechanism causing tailing. The two models yielded almost identical transport results when vertical correlation lengths of silty clay were matched. Several practical implications relevant for characterization of low conductive units were identified and briefly discussed.
\end{abstract}

\title{
1. Introduction
}

Groundwater contamination is a serious worldwide problem - billions of dollars are spent annually on remediating contaminated sites (National Research Council, 1994, 2004, 2012). Frequently, cleanup technologies are successful in removing the bulk, but not the entire quantity 
of contaminants (National Research Council, 1994, 2004, 2012). Residual contamination often persists for long time periods, generating contaminant concentration above cleanup targets.

The mechanisms responsible for this phenomenon, termed "contaminant tailing", are often site specific. This paper explores the relationship between geologic heterogeneity and contaminant tailing for a well-characterized aquifer. In this work "tailing" is defined in terms of asymmetry in the travel time distribution of particles released into an aquifer under uniform source and natural gradient conditions. When particle travel time is represented graphically as a BTC (breakthrough curve or cumulative distribution function), tailing is observed if a large proportion of particles exhibit substantially longer travel times relative to the median. The shape of the BTC tail captures important aspects of contaminant transport, particularly for remediation applications where it is desired to remove a very large fraction of emplaced contaminants. For example, BTC tailing is a way of characterizing "back diffusion," which occurs when contaminants become trapped in low-permeability materials and require extended operation of remediation systems as they diffuse back out into higher-permeability material.

Contaminant tailing in porous formations is partially caused by slow advection and diffusion through low-conductive units (such as silt and clay lenses/layers) as demonstrated by various field experiments (e.g. Rasa et al., 2011; Liu and Ball, 2002; Chapman and Parker, 2005; Parker et al., 2008), laboratory tests (e.g. Levy and Berkowitz, 2003; Sillman and Simpson, 1987), and numerical simulations (e.g. Fiori et al., 2006; Jankovic et al., 2009; Seyedabbasi et al., 2012). Sorption processes also produce delays in contaminant transport (e.g. Roberts et al., 1986; Burr et al., 1994; Dentz and Castro, 2009; Maghrebi et al., 2014).

This manuscript examines the coupled impacts of slow advection, diffusion, and sorption on contaminant tailing. These impacts were investigated using numerical simulations that were 
based on two models of subsurface heterogeneity which differ in structure and in mathematical framework that was used to simulate flow and transport and to quantify contaminant tailing. The models are based on alternative geostatistical descriptions of the hydraulic conductivity $K$ and perchloroethene (PCE) sorption distribution coefficient $K_{d}$ of highly heterogeneous sediment in an exposure of the Borden aquifer located approximately $2 \mathrm{~km}$ north-west of the StanfordWaterloo experimental site at Canadian Forces Base Borden, Ontario, Canada (Weissmann et al. 2015). The main goal of the present study is to quantify the impact of model selection on tailing and to identify the impacts of different geologic materials and their geometric and material properties on tailing. Additionally, we aim to increase the general understanding of tailing in porous formations. While the models are initially built using realistic geostatistical descriptions of the formation, we are not aiming to build the best predictive model for the formation found at our site.

Heterogeneity models used for transport simulations are generally based on simplified statistical descriptions of heterogeneous formations (e.g., Gelhar, 1993; de Marsily et al., 2005). Most models, such as commonly used multi-Gaussian model, are functions of the mean, variance, and overall $K$ correlation lengths, and do not include information derived from higher order statistical measures, such as connectivity (related to correlation lengths) of different materials. However, this simplification introduces uncertainty in the modeling process, as numerical and analytical studies have shown that the transport behavior of aquifers with the same mean, variance and overall $K$ correlation lengths, but different higher order measures, can be different (Zinn and Harvey, 2003; Soltanian et al., 2014).

Similar to $K$ heterogeneity, heterogeneity in sorption properties is also known to affect the transport of hydrophobic contaminants, although there is, in general, limited availability of field 
data to support suitable models. In this manuscript, sorption is assumed to be a linear equilibrium process characterized by a heterogeneous distribution coefficient $K_{d}(\boldsymbol{x})$ with an associated retardation factor of $R(\boldsymbol{x})=1+\rho_{b} \cdot K_{d}(\boldsymbol{x}) / n$, where $\rho_{b}$ is the bulk density and $n$ is the porosity. In addition to this assumption, one of two simplifications is typically used to create models of heterogeneous $K_{d}(\boldsymbol{x})$ fields: (1) $K_{d}(\boldsymbol{x})$ is modeled as a random space function independent of $K(\boldsymbol{x})$ (e.g. Burr et al., 1994; Dentz and Castro, 2009), or (2) $K_{d}(\boldsymbol{x})$ is obtained using a simple linear relationship between $\ln K_{d}(\boldsymbol{x})$ and $\ln K(\boldsymbol{x})$ (e.g. Cvetkovic and Shapiro, 1990; Bellin et al., 1993; Tompson, 1993; Burr et al., 1994; Tompson et al., 1998; Deng et al., 2013). Neither simplification is supported by the few available field data sets (Allen-King et al., 1998; AllenKing et al., 2006; Robin et al., 1991; Foster-Reid, 1994). As a result, the necessary simplification used to represent the spatial distribution of $K_{d}(\boldsymbol{x})$ introduces additional uncertainty in interpretation of results of the modeling process.

Recent advances in site characterization techniques have enabled very high resolution descriptions of aquifer heterogeneity that capture mm-scale variability in aquifer materials (e.g., Weissmann et al. 2015). However, incorporating such details into numerical models of flow and contaminant transport can be computationally prohibitive if the goal is to capture tailing and back diffusion processes. As an alternative, this work explores the application of indicator geostatistics coupled with an "inclusions-based" modeling approach to represent heterogeneity in both $K(\boldsymbol{x})$ and $K_{d}(\boldsymbol{x})$ fields. The inclusion-based approach does not require the raster-type depiction of heterogeneity needed for grid-based models. It is capable of representing the correlation structure and connectivity of heterogeneous properties through the assemblage of inclusions that represent the various aquifer materials. Such a statistical representation of the aquifer may not be suitable for generating accurate predictions of local contaminant 
concentrations, but can capture the macroscopic behavior in a manner that illuminates the relationship between statistical heterogeneity and important aspects of contaminant transport such as tailing.

The inclusions-based model (referred to as the inclusion model hereafter) was based on the indicator geostatistical analysis of a detailed dataset collected at our site. This 3D dataset was created using high-resolution photography and ground-based LIDAR techniques that were applied to several vertical outcrop panels exposed at the site (Weissmann et al., 2015). The $K(\boldsymbol{x})$ and $K_{d}(\boldsymbol{x})$ models used here were built using the geostatistical description of individual materials found in the formation (with unique $K$ and $K_{d}$ values (Allen-King et al., 2015)), instead of the overall $K(\boldsymbol{x})$ measures (mean, variance, overall correlation length) and assumptions of $K(\boldsymbol{x})$ $K_{d}(\boldsymbol{x})$ correlations. The description includes materials' volume fractions and correlation lengths. The model represents each individual material with a set of identical ellipsoidal inclusions that are randomly populated in the space. The size, shape, and the number of inclusions were selected based on the directional correlation lengths and the volume fraction of each material. The values for $K$ and $K_{d}$ are based on published values for the material for the Borden Aquifer (Allen-King et al., 2015).

Most solute transport simulations reported here were based on the inclusions model. This model is used to investigate transport and tailing at the spatial scale characterized by Weissmann et al. (2015) (40m horizontal and 10m vertical) and larger scales, and to investigate tailing sensitivity on material and geometric properties of different geologic materials. In addition to this inclusions model, another model was created based on the transitional probability geostatistics (Carle and Fogg, 1996, 1997) using TPROGS code (Carle, 1999) for comparison with the inclusions model. This model also assigns single $K$ and $K_{d}$ values for each material. This 
model, termed transitional probability (TP)-based model here, is limited (due to numerical constraints) to the spatial scale characterized by Weissmann et al. (2015). Sensitivity of the TPbased model on material properties is also included.

Because of generally narrow distributions of $K(\boldsymbol{x})$ and $K_{d}(\boldsymbol{x})$ within each material, each material is represented by a single $K$ and a single $K_{d}$ value in each realization of the models.

The rest of this manuscript is organized as follows. A brief discussion of the indicator and the overall geostatistics of the Borden formation are presented in Section 2 followed by the description of inclusions and TP-based heterogeneity models. The transport results for the heterogeneity models are compared in Section 3. This is followed by several sensitivity analyses of geometric and material properties for both models in Section 4. Finally, the concluding remarks are presented at the end.

\section{Heterogeneity Models}

\subsection{Geostatistics of Field Data}

The contaminant transport models were based on data obtained from a sand quarry located approximately $2 \mathrm{~km}$ north-west of the Stanford-Waterloo (SW) experimental site at the Canadian Force Base Borden, Ontario, Canada. Several vertical outcrop panels up to $20 \mathrm{~m}$ long and $1.5 \mathrm{~m}$ in height (Figure 1) covered an area about 40x10m (Weissmann et al., 2015). The top of exposure was located in material that was stratigraphically equivalent to sediments observed near the bottom of cores from the SW site - approximately $3 \mathrm{~m}$ below the ground surface. The aquifer sediments were mapped into individual material groups using high-resolution photography, ground-based LIDAR, and field outcrop analysis, as described in Weissmann et al. (2015). 
For the present analysis, only panels AU1-4 (4 panels), AL1, DU, DL, and E (about 1.5 million points) were used (panel specifics are described in detail in Weissmann et al. (2015)). Lower panels were excluded because of their limited spatial extent. The created dataset of around 1.5 million points was used to obtain indicator geostatistical descriptions of four material groups (sandy gravel, lenticular sands, tabular sands, and silty clay) found at the site.

Experimental indicator semi-variograms were computed first using the GSLIB code (Deutsch and Journel, 1997), parallelized for efficiency, for each material group. The outcrop panels were analyzed separately because of minor inconsistencies in mapping of adjacent outcrop panels (AU1-4). Sensitivity to numerical GSLIB parameters was found to be insignificant due to the large size of the dataset. Exponential variogram models were fit using an automated fitting procedure with weights (assigned to each experimental semi-variogram value) proportional to the number of pairs. An example of results is presented in Figure 2.

Finally, overall correlation lengths for each material group were computed as weighted average of correlation lengths (based on the exponential model) of individual panels, with weights set proportional to percentages of the material in each outcrop panels. The final results are presented in Table 1. Additionally, Table 1 contains volume fractions and the representative $K$ and PCE $K_{d}$ determined by matching the material groups to the lithofacies (of known properties) defined by Allen-King et al. (2015).

Two samples from the silty clay material group from the top of panel AL2 were collected at our site and their $K$ was measured using falling-head method (ASTM D5084-10, 2010) in laboratory (SJB services, Inc, Hamburg, NY). The laboratory measured $K$ (at average ambient temperature of $20^{\circ} \mathrm{C}$ ) were reduced by a factor of 1.3 to account for the change in the viscosity 
from $20^{\circ} \mathrm{C}$ to $10^{\circ} \mathrm{C}$ (average groundwater temperature at Borden). The estimated $K$ values were rather consistent: $6.87 \times 10^{-7}$ and $5.87 \times 10^{-7} \mathrm{~cm} / \mathrm{s}$. The average $K$ of these two measurements, $6.37 \times 10^{-7} \mathrm{~cm} / \mathrm{s}$, was selected as the representative $K$ of silty clay.

The highly sorbing sandy gravel was found with negligible volume fraction of just $0.7 \%$. The low- $K$ silty clay was found with high volume fraction of $23.4 \%$. The volume fraction of silty clay was found to be considerably lower for upper portions of the formation (closer to elevations of SW cores) indicating non-stationarity of the $K(\boldsymbol{x})$ field. The effects of this non-stationarity are not examined in this paper - both models developed here simulate transport through stationary formations.

The goal of the present research was not to create models that best describe transport and tailing at the site, but to use site geostatistical descriptions to guide the sensitivity analyses and to quantify the impact of two different models on predictions of tailing. Hence, uncertainty in the geostatistical measures reported in Table 1 does not constrain the general findings related to the influence of heterogeneity on contaminant transport.

The overall geostatistics of the $\ln K(\boldsymbol{x})$ and PCE $\ln K_{d}(\boldsymbol{x})$ fields of the formation were computed using the same approach, by replacing indicator variograms with traditional (nonindicator) variograms. The variance of $\ln K(x)$ field equaled 18.9, much larger than the values found earlier at the SW site (0.2-0.6). The large variance of $\ln K(x)$ field is a direct function of conductivity and volume fraction of fine materials in formation. The variance is large for the site due to presence of very low- $K$ silty clay with high volume fraction (23.4\%) compared to SW site which is formed by relatively low- $K$ silt with small volume (Allen-King et al., 2006). The overall correlation lengths were $I_{h}=1.95 \mathrm{~m}$ and $I_{v}=0.09 \mathrm{~m}$ for the $\ln K(x)$ field, and $2.30 \mathrm{~m}$ and $0.10 \mathrm{~m}$ for 
the $\ln K_{d}(\boldsymbol{x})$ field in the horizontal and the vertical directions, respectively. These values are consistent with the values found by earlier studies at the SW site (0.91-8.3m in horizontal and $0.07-0.34 \mathrm{~m}$ in vertical direction for $\ln K(\boldsymbol{x})$ field; and $1.33-1.8 \mathrm{~m}$ in horizontal and $0.05-0.07 \mathrm{~m}$ in vertical direction for $\ln K_{d}(\boldsymbol{x})$ field) (Woodbury and Sudicky, 1991; Allen-King et al., 1998; Allen-King et al., 2006; Allen-King et al., 2015).

\subsection{Inclusions Model}

The inclusions model used here is a special case of the general multi-indicator model (Dagan et al., 2003) that was used to create two- and three-dimensional isotropic and anisotropic models of heterogeneous formations (e.g. Jankovic et al., 2003b, 2006; Fiori et al., 2005, 2013; Firmani et al., 2009; Suribhatla et al., 2011; Maghrebi et al., 2014). Similar to past studies, the present inclusions model is simple: it does not replicate complex subsurface architectures and variability in material lengths of different materials.

The model's ellipsoidal domain filled with inclusions was $195 \mathrm{~m}(100 \ln K(\boldsymbol{x})$ horizontal correlation lengths $\left.I_{h}\right)$ long and wide, and $9 \mathrm{~m}\left(100 \ln K(\boldsymbol{x})\right.$ vertical correlation lengths $\left.I_{v}\right)$ tall (Figure 3). The ellipsoidal shape ensures that flow inside the domain is, in the average, uniform. The model scale is larger than the site scale characterized by Weissmann et al (2015), as explained earlier, since the model is also used to investigate transport at scales larger than the scale of the Borden site.

The model domain was filled with four groups of identical horizontal oblate ellipsoidal inclusions that were randomly emplaced without overlaps. The spatial distribution of inclusions was uniform. Each group of inclusions represents one material group found in the formation. The semi-axes of inclusions ( $a$ and $b$ ) in the horizontal and the vertical directions were set to $4 / 3$ of the horizontal and the vertical correlation length of the material group, following Jankovic et al. 
(2003b) and Suribhatla et al. (2011). For each material, the number of inclusions was computed using the volume fraction of the material group. Finally, the appropriate $K$ and $K_{d}$ values (Table 1) were assigned to all inclusions for a given material and realization of the heterogeneity model.

Random placement in space up to the maximum packing density was accomplished using the random sequential adsorption method (Meakin and Jullien, 1992) that was extended to 3D. The presence of intersections was checked using the Wang and Wang (2001) algorithm to ensure that no overlaps are present. The number of inclusions of all groups was 17,664 (11,496 sandy gravel inclusions, 2,454 lenticular sands inclusions, 2,324 tabular sands inclusions, and 1,390 silty clay inclusions). The resulting volume fractions at maximum packing density of $43.0 \%$ were: $0.3 \%$ sandy gravel, $22.0 \%$ lenticular sands, $10.6 \%$ tabular sands, and $10.1 \%$ silty clay. The relative volume fractions are defined here as the ratios of the volume fractions of each material group to the overall volume fraction (packing density). The relative volume fractions match values reported in Table 1. While the relative volume fractions match values reported in Table 1, the absolute ones do not match actual volume fractions. This issue will be discussed later in the manuscript.

The effective $K$ and $K_{d}$ of the ensemble of inclusions were computed and assigned to the homogeneous background, following previous inclusions-based modeling studies (e.g. Jankovic et al., 2003b, 2006; Maghrebi et al., 2013). The self-consistent averaging (Dagan, 1989; Suribhatla et al., 2011) was used to compute the components of the effective conductivity in the horizontal direction $\left(K_{e f h}\right)$ and the vertical direction $\left(K_{e f v}\right)$ using Table 1 data (conductivity, volume fractions, and the ratio of horizontal to vertical correlation lengths of material groups). These components equal $K_{\text {efh }}=1.34 \times 10^{-2} \mathrm{~cm} / \mathrm{s}$ and $K_{\text {efv }}=8.68 \times 10^{-4} \mathrm{~cm} / \mathrm{s}$. The values were used as 
background hydraulic conductivity in horizontal and vertical directions. The anisotropy in the effective conductivity is attributed to the presence of long and thin silty clay inclusions.

The effective sorption distribution coefficient $K_{\text {def }}=0.52 \mathrm{~mL} / \mathrm{g}$ was computed as the weighted arithmetic average of inclusions' $K_{d}$, following Rajaram (1997); Fernandez-Garcia (2004, 2005); Deng et al. (2013), Maghrebi et al. (2013), and Soltanian et al. (2015) with weights proportional to the volume fractions of the material groups. Typical Borden-specific parameters were adopted for bulk density and porosity: $\rho_{b}=1.81 \mathrm{~g} / \mathrm{cm}^{3}$ and $n=0.33$ (Mackay et al., 1986) and used with $K_{d e f}$ to compute the effective retardation factor $R_{e f}=3.85$ which was assigned to the homogenous background.

To simulate steady-state groundwater flow, the heterogeneous domain was subject to uniform flow of specific discharge (Darcy velocity) $U$. The resulting flow solution was obtained using the analytic element method (Jankovic and Barnes, 1999). Contaminant transport was simulated using the particle tracking method (Tompson et al., 1988) by instantaneous release of a uniformly spaced 150x150 grid of particles over an area $97.5 \mathrm{~m}$ wide and $4.5 \mathrm{~m}$ tall, placed inside the domain orthogonal to flow. Model output was expressed in terms of breakthrough curves (BTCs), which quantified the fractions of initial contaminant mass $M_{0}$ crossing a set of 10 equally spaced control planes, as functions of time. The control planes were placed downstream of the injection plane and separated by $9.75 \mathrm{~m}$. A portion of $M_{0}$ that was attached to each particle was set based on local groundwater velocity at injection location. This injection mode simulates flux-proportional injection as explained in Jankovic and Fiori (2009).

To compare the BTCs generated by two heterogeneity models, the BTC times were normalized by multiplying times with $V_{M} / V_{B}$ where $V_{M}$ is model plume velocity and $V_{B}$ was set to 
a representative plume velocity at the Borden site: $V_{B}=0.1 / R_{e f}(\mathrm{~m} / \mathrm{d})(0.1 \mathrm{~m} / \mathrm{d}$ represents typical Borden groundwater velocity, following Mackay et al., 1986; Sudicky, 1986; and Allen-King et al., 2006). $V_{M}$ was computed for each control plane as the distance between the injection plane and the control plane, divided by the average travel time to the control plane. This velocity ranged from $0.77 U$ to $0.79 U$ for various control planes and simulations with different amounts of molecular diffusion (described later). As expected, the normalized plume velocity range was narrow and close to plume velocity in the far field (outside the heterogeneous domain) $U / n / R_{e f}=0.79 U$. Hence, effective properties of the heterogeneous medium appear to have been reasonably estimated.

The numerical simulations were conducted using two values of the effective molecular diffusion coefficient $D_{\text {eff }}$ which takes into account the porosity, tortuosity, and constrictivity of a porous formation. $D_{\text {eff }}$ was computed by setting Peclet number $P e=(U / n) \cdot I_{h} / D_{\text {eff }}$ to $P e=10^{4}$ and

$P e=10^{5}$. Selection of Peclet number is motivated by PCE $D_{e f f}=0.15 D_{a q}$ (following Grathwohl, 1997), where $D_{a q}$ is the molecular diffusion coefficient of PCE in water that equals $8.2 \times 10^{-6}$ $\mathrm{cm}^{2} / \mathrm{s}$ (SeyedAbbasi et al., 2012), and representative groundwater velocity of $0.1 \mathrm{~m} / \mathrm{d}$, which results in $P e \approx 18,000$.

\subsection{Silty Clay-Only Inclusions Model}

As discussed subsequently, the silty clay was determined to be the most important material influencing the tailing. However, the random packing algorithm generated silty clay inclusions with the volume fraction of just $10.1 \%$, considerably less than the measured volume fraction of 23.4\%. Therefore, to preserve the site-specific volume fraction of silty clay material, a silty clayonly inclusions model was created with silty clay inclusions of volume fraction equal to $23.4 \%$. 
Other inclusions were excluded. Approximately 3,200 inclusions were placed randomly into a homogeneous background of the same domain size. The silty clay inclusions were assigned the same size (horizontal semi-axis $a$ and vertical semi-axis $b$ ) and same $K$ and $K_{d}$ as the silty clay inclusions in the original model.

The background of this silty clay-only model represents the material groups other than silty clay. Hence, the random packing limitation of inclusions model was resolved here by assigning the most prevalent materials (sands and gravel) to the background and filling the domain with just silty clay inclusions. The effective properties of sand and gravel materials were assigned to the background. The components of the effective $K$ were computed using self-consistent averaging (Dagan, 1989; Suribhatla et al, 2011) without silty clay material group (sands and gravel only) and equaled $K_{b h}=1.83 \times 10^{-2}$ and $K_{b v}=1.81 \times 10^{-2} \mathrm{~cm} / \mathrm{s}$. The effective (weighted arithmetic average) $K_{d}$ of sands and gravel materials equaled $0.48 \mathrm{~mL} / \mathrm{g}\left(R_{b}=3.61\right)$.

Flow and transport solutions were obtained using the same methodologies as for the original model. The average plume velocity for various control planes ranged from $V_{M}=0.59 U$ to $0.60 U$ for $P e=10^{4}$ and from $0.50 U$ to $0.53 U$ for $P e=10^{5}$. All velocities are smaller than the plume velocity in the far field $U / n / R_{b}=0.84 U$. The velocities are lower since the effective conductivity of the heterogeneous domain is lower than the background conductivity because of the presence of silty clay (which is absent in the far field). Finally, the travel times in the BTCs were multiplied by $V_{M} / V_{B}$, as explained before. As before, transport simulations were carried for $P e=10^{4}$ and $10^{5}$. 
The sensitivity of the model results to vertical and lateral plume sizes were investigated by considering two plume halves and comparing results from plume halves to full-plume results, which were equivalent for all test cases.

\subsection{TP-based Model}

The TP-based model was created using the TPROGS code (Carle, 1999) based on the transitional probability geostatistics computed by Weissmann et al. (2015) for four material groups found at the Borden site. A single realization of the TP-based model (Figure 4), conditioned on $0.3 \%$ of the dataset, was used to create a heterogeneous domain of dimensions $30 \times 10 \times 12 \mathrm{~m}\left(15.4 I_{h} \times 5.1 I_{h} \times 133.3 I_{v}\right)$ in the longitudinal, lateral (transverse), and vertical directions, respectively. Despite the observed vertical correlation structure observed in the field data and used as input to transitional probability algorithm (Weissmann et al.,2015), the simulated vertical distribution of silty clay in the TP-based model here was approximately uniform because realization of the heterogeneous domain was conditioned on a small fraction (just $0.3 \%$ ) of the dataset.

The model was discretized into uniformly sized cells of dimensions $10 \times 10 \times 2 \mathrm{~cm}$. The total number of cells equaled $18.27 \times 10^{6}$. Further decrease in cell dimensions (and corresponding increase in the number of cells) was not possible due to observed computational limitations of the TPROGS quenching algorithm, which failed to converge. The output of the TPROGS code consisted of material indices for all model cells (with no background), and the $K$ and $K_{d}$ values were assigned based on these indices and the material properties reported in Table 1. 
To simulate steady-state groundwater flow, the domain generated by the TP-based model was subject to a unit head gradient in the longitudinal direction. The flow solution was obtained using the node-centered finite difference code presented in Jankovic et al. (2013). The code was run without $K$ averaging by using a point $K$ value instead of cell-average $K$ value. The impact of this approximation was checked by running the code again with geometric averaging applied in the flow direction. Results were practically identical. The remaining sensitivity analyses were run without $K$ averaging. The horizontal effective hydraulic conductivity of TP-based model was computed numerically and equaled $K_{\text {efh }}=1.33 \times 10^{-2} \mathrm{~cm} / \mathrm{s}$, which is almost the same as the horizontal effective conductivity of inclusions model reported earlier $\left(1.34 \times 10^{-2} \mathrm{~cm} / \mathrm{s}\right)$. The theoretical effective conductivity (based on self-consistent averaging) of the TP-based model realization, using actual TP-based model volume fractions and correlation lengths of different material groups reported in the next section (Table 2), is also similar and equals $1.30 \times 10^{-2} \mathrm{~cm} / \mathrm{s}$. These similarities support the decision of using the self-consistent averaging for this model's background. To our knowledge, this was the first investigation of performance of self-consistent averaging using TP-based models.

Contaminant transport was simulated using the semi-analytic particle tracking method of Pollock (1994). To reduce boundary effects, a collection of 22,500 (150x150) particles was released in a flux-proportional mode into an injection plane placed $3 \mathrm{~m}$ downstream of the upstream domain boundary. The particles were released over an area $8 \mathrm{~m}$ wide and $10 \mathrm{~m}$ tall perpendicular to the mean flow direction. The size of the injection area was checked by dividing the plume at the injection plane into two halves (top and bottom) which yielded almost identical results. Hence, a single realization (for a given set of input parameters) was sufficient to quantify 
transport. The BTCs were computed for a set of 24 control planes spaced at uniform $1 \mathrm{~m}$ intervals.

The travel times in the BTCs were multiplied by $V_{M} / V_{B}$, as done earlier, to enable the comparison of models. The plume velocity $V_{M}$ ranged from 1.05 to $1.11 V_{G} / R_{e f}$ for various control planes in $P e=10^{4}$ simulation, where $V_{G}$ is the average grid velocity and $R_{e f}$ was computed using the actual volume fractions of different materials in the TP-based model realization and equaled 3.81. $V_{M}$ ranged from 0.93 to $1.04 V_{G} / R_{e f}$ for various control planes in $P e=10^{5}$ simulation.

\subsection{Geostatistical Analyses of Models' Realizations}

Geostatistical analyses of model realizations are summarized in Tables 2 and 3. As shown in the Table 2 and 3, the inclusions model matched the indicator correlation lengths of the individual materials reported in Table 1. However, the volume fractions of the individual material groups were not well represented, as discussed earlier, due to the limitation of random packing of inclusions (presence of the background). The lower variance of the $\ln K(\boldsymbol{x})$ field is attributed to the lower volume fraction of the silty clay material. In contrast, the silty clay-only inclusions model preserved the volume fraction of silty clay and hence, mean and variance of the $\ln K(\boldsymbol{x})$ field.

The TP-based model correctly represented the volume fractions of all material groups, although the indicator correlation lengths were somewhat different from the values reported in Section 2.1. For example, the correlation length of the silty clay was found to be $2.74 \mathrm{~m}$ in the horizontal and $0.17 \mathrm{~m}$ in the vertical directions. Corresponding values from Section 2.1 (Table 1) 
are $3.66 \mathrm{~m}$ and $0.10 \mathrm{~m}$. The match of simulated values for the overall correlation lengths of $\ln K(\boldsymbol{x})$ and $\ln K_{d}(\boldsymbol{x})$ was better.

\section{Sensitivity of Tailing on Model Selection}

\subsection{Impact of Silty Clay Material on Tailing}

The degree of simulated contaminant tailing for both the inclusions and the TP-based models was dominated by the silty clay material, as demonstrated by the BTC comparisons shown in Figure 5, where the BTC of the inclusions model for $P e=10^{4}$ and control plane $19.5 \mathrm{~m}$ from the injection plane and the BTC for the same model with the silty clay inclusions only are compared. In order to compare the influence of silty clay in the TP-based model, we assigned all categories, except the silty clay, to the properties of the homogeneous background of the silty clay-only inclusions model (where background represents the average properties of sands and gravel). A comparison of BTCs for $P e=10^{4}$ and control plane $20 \mathrm{~m}$ downstream of the injection plane for TP-based model and the silty clay-only TP-based model is also presented in Figure 5. As before, the travel times in the BTCs computed using two models were multiplied by $V_{M} / V_{B}$. The comparison suggests that materials other than the silty clay can be combined into a homogenous background, thus implying that the dominant influence on BTC tailing is produced by silty clay. The original inclusions model is replaced by the silty clay-only inclusions model (which matches the overall volume fraction of silty clay at the Borden site, as discussed earlier) in the remaining part of the manuscript. No changes to the TP-based model were made.

\subsection{Comparison of Models}


The comparison between the transport results obtained from the silty clay-only inclusions model and TP-based model are presented in Figure 6 for $P e=10^{4}$ and $P e=10^{5}$ at control plane $27.5 \mathrm{~m}$ from the injection plane (silty clay-only inclusions model) and control plane $24 \mathrm{~m}$ from the injection plane (the last control plane for the TP-based model). Different control planes were selected since the overall $\ln K(\boldsymbol{x})$ horizontal correlation lengths of these models $\left(I_{h M}\right)$ are different (Table 3) - both control planes are at $8.8 I_{h M}$ downstream of the injection plane. To account for different $I_{h M}$, the BTC times were expressed in dimensionless terms $t V_{M} / I_{h M}$.

The TP-based model generated more pronounced tailing than the silty clay-only inclusions model. This behavior was attributed to the failure of the transitional probability algorithm to correctly reproduce the vertical correlation structure, which was more accurately represented by the inclusions model. To facilitate comparisons between the two modeling approaches, the silty clay-only model was adjusted by stretching the inclusions in the vertical direction so that the vertical correlation length of the silty clay inclusions $(0.08 \mathrm{~m}$, as reported in Table 2$)$ matched that of TP-based model $(0.17 \mathrm{~m}$, Table 2$)$. The BTC produced by the stretched inclusions model (where particles spend more time inside silty-clay inclusions) is very similar to BTC produced by the TP-based model, despite differences in the structures of two models and differences in the numerical methodologies behind the models. This consistency was also observed for other control planes with different distances (in terms of $I_{h M}$ ) from the injection plane. Hence, for the conditions of these numerical experiments, BTC shape was insensitive to selection of the model as long as the volume fractions and the vertical correlation lengths of silty clay were appropriately matched. The impact of the horizontal correlation length of the silty clay is examined later in this manuscript. 


\section{Impact of Geometric and Material Properties on Tailing}

The silty clay material was identified as the most important material affecting the simulated BTCs. To further explore the influence of variability in aquifer materials on tailing, the sensitivity of tailing to the geometric and material properties of silty clay is investigated first. This is followed by evaluation of the sensitivity of tailing to properties of the highly-sorbing sandy gravel material. As before, the travel times in the BTCs computed using the two models were multiplied by $V_{M} / V_{B}$ for all figures presented in this section. Although the transport results are presented for only a few control planes, similar trends were observed at other locations.

\section{1. $K$ of Silty Clay}

The sensitivity of simulated BTC tailing was investigated by varying the $K$ of the silty clay over a few orders of magnitude compared to the $K$ of silty clay at our site $\left(6.37 \times 10^{-7} \mathrm{~cm} / \mathrm{s}\right.$-Table 1). The transport results are presented in Figure 7 for $P e=10^{4}$ for both the silty clay-only inclusions model and the TP-based model.

Figure 7 shows that the transport and tailing in both models are insensitive to actual $K$ of silty clay. This is explained by findings of Jankovic et al. (2009) and Maghrebi et al. (2014) who identified a cutoff hydraulic conductivity contrast $\kappa_{c}=K_{d} / K_{b}$, where $K_{c}$ is the cutoff conductivity of the inclusions and $K_{b}$ is the background conductivity, that separates the diffusion-dominated and advection-dominated transport regimes. The transport is dominated by diffusion if $\kappa<\kappa_{c}$ and by advection if $\kappa>\mathcal{K}_{c}$, where $\kappa=K / K_{b}$ is the actual hydraulic conductivity contrast (and $K$ is the 
actual conductivity of inclusions). In the silty clay-only inclusions model the actual conductivity contrast of the silty clay inclusions is $6.37 \times 10^{-7} / 1.83 \times 10^{-2}=3.5 \times 10^{-5}$, which is considerably lower than the thin inclusions cutoff contrast of $\kappa_{c}=24.4 / P \mathrm{e}^{0.7}=3.9 \times 10^{-2}$ (Maghrebi et al., 2014) for $P e=10^{4}$ and $\kappa_{c}=24.4 / P \mathrm{e}^{0.7}=7.7 \times 10^{-3}$ for $P e=10^{5}$.

Although an explicit background is absent in the TP-based model, the sands units used here have similar conductivities. These are effectively equal to the background $\mathrm{K}$ of the silty clayonly inclusions model. The insensitivity of the BTCs to the $K$ of silty clay material indicates that the exact measurement of $K$ of silty clay in applications may not be necessary if $K$ is low enough and transport is dominated by diffusion.

\section{2. $K_{d}$ of Silty Clay}

Sensitivity of tailing in the silty clay-only inclusions model and the TP-based models to the silty clay $K_{d}$ was investigated by changing the $K_{d}$ by plus/minus one standard deviation, or 0.38 $\mathrm{mL} / \mathrm{g}$ (Allen-King et al., 2015) from the $K_{d}$ reported in Table $1(0.66 \mathrm{~mL} / \mathrm{g})$. The results are presented in Figure 8 for $P e=10^{4}$ for a control plane $19.5 \mathrm{~m}$ from the injection plane for the silty clay-only inclusions model and $20 \mathrm{~m}$ from the injection plane for the TP-based model. Results for non-sorbing plumes are included as well.

The tailing results are highly sensitive to the silty clay $K_{d}$ because diffusive contaminant movement inside the silty clay is affected by sorption. The implication of this finding is that 
accurate determination of the $K_{d}$ of low- $K$ materials is required for robust modeling of contaminant tailing.

\subsection{Geometry and Volume Fraction of Silty Clay}

Impacts of geometry and volume fractions of the silty clay materials on large-scale (beyond scale of the TP-based model) transport and tailing were investigated using the silty clay-only inclusions model. The vertical semi-axis $(b)$ of thin silty clay inclusions (and corresponding vertical correlation length) has stronger impact on tailing than horizontal semi-axis $(a)$. This is because the contaminant removal out of thin low- $K$ silty clay inclusions is facilitated by the shorter vertical extent of such inclusions, as demonstrated in Figure 9 where one semi-axis of inclusions is fixed while the other one is varied. The volume fraction of silty clay inclusions was kept constant at $23.4 \%$ for all realizations. Tailing is quantified at different $M / M_{0}$ fractions (from $M / M_{0}=0.992$ to 0.999$)$ for $P e=10^{4}$ at control plane $48.75 \mathrm{~m}$ from the injection plane. As seen in Figure 9, the impact of $a$ on tailing is negligible for thin inclusions (large $a / b$ ), while the impact of $b$ is significant, with higher impacts for higher $M / M_{0}$ values. Thus, the exact estimation of the vertical extent of low conductive materials is important for robust predictions of tailing in practice, especially for high $M / M_{0}$.

The impact of geometry and volume fraction of silty clay inclusions on tailing was further investigated by varying $a / b$ ratio and the volume fraction of silty clay. $a$ was fixed to $4.88 \mathrm{~m}$ (corresponding to horizontal correlation length of $4.88 \times 3 / 4=3.66 \mathrm{~m}$ reported in Table 1 ) and $b$ was varied. The sensitivities of transport and tailing on the shape ratio for fixed silty clay volume fraction of $23.4 \%$, and on the volume fraction of the silty clay inclusions for fixed $a / b=37.5$ (the ratio of horizontal and vertical correlation lengths from Table 1) are shown in Figure 10. 
Transport is quantified for $P e=10^{4}$ at control plane $97.5 \mathrm{~m}$ from the injection plane. Tailing is increased by decrease in $a / b$ (increase in $b$ ) and by increase in the volume fraction of silty clay, as expected and shown in Figure 10. However, when $M / M_{0}$ approached unity, different volume fractions yielded very similar results for the range of volume fractions investigated here. The practical implication of this finding is that perhaps a few low-conductivity lenses, or even a single low-conductive lens, may produce contaminant tailing.

Variations in both $a / b$ and the volume fraction were investigated next in a systematic fashion for $P e=10^{4}$ by computing time (in years) that corresponds to $M / M_{0}=0.999$ for the same control plane (97.5m away from the source). Results are included in Figure 11 which shows that tailing is more sensitive to the shape ratio (i.e. thickness of the low conductive inclusions) than the volume fraction. This implies that (in practice) it is more important to properly characterize the thickness of low- $K$ lenses/layers, than the volume fraction of such units. The impacts of volume fraction on the other parts of the BTCs (e.g. lower $M / M_{0}$ ) were stronger.

\section{4. $K_{d}$ and Volume Fraction of Sandy Gravel}

The impact of highly-sorbing sandy gravel material on tailing was found to be negligible in our numerical simulations due to the very low volume fraction of sandy gravel at the site. The sensitivity of tailing on presence (volume fraction) of gravel and $K_{d}$ of highly-sorbing sandy gravel material was investigated. These findings may be useful for heterogeneous formations where highly-sorbing sandy gravel is present with higher volume fractions.

A new inclusions model was developed with just sandy gravel inclusions placed into a homogeneous background of the silty clay-only inclusions model. Both the volume fraction and $K_{d}$ were varied: volume fractions of $10 \%, 20 \%$, and $38 \%$ were used in addition to the original 
volume fraction of $0.7 \%$. Similarly, $K_{d}=6 \mathrm{~mL} / \mathrm{g}$ was used in addition to the original $K_{d}=3 \mathrm{~mL} / \mathrm{g}$ (Table 1). Transport results presented in Figure 12 are for $P e=10^{4}$ and control plane approximately $30 \mathrm{~m}$ from the injection plane.

The results indicate that highly-sorbing sandy gravel material can cause plume delays, but not tailing. Hence, regardless of the volume fraction, if sorption is represented using linear sorption isotherms characterized by $K_{d}$ between 3 and $6 \mathrm{~mL} / \mathrm{g}$, sandy gravel can cause plume delays, but the influence of sandy gravel on plume tailing is small relative to influence of silty clay. The present assumptions about the sorption process should be examined in the future since, for example, nonlinearity in sorption isotherms can produce different plume behavior (Singh et al., 2014) and perhaps tailing.

\section{Conclusions}

The influence of aquifer heterogeneity on simulated BTC tailing was investigated using two alternative models that differed in structure and mathematical framework. Both models were based on indicator data collected from the highly heterogeneous outcrop analogue of the Borden aquifer approximately $2 \mathrm{~km}$ north-west of the Stanford-Waterloo (SW) experimental site. The

first model was made with four groups of non-overlapping ellipsoidal inclusions that were randomly populated in space. Each group of inclusions represented a material group found at the site. The second model was based on transitional probability geostatistics of material groups. Each material groups in both models was characterized with a uniform representative hydraulic conductivity $K$ and sorption distribution coefficient $K_{d}$ in each model realization. Various 
realizations were used to compare model results and to investigate models' sensitivities on material and geometric properties of material groups.

For the conditions of these simulations, the silty clay material was found to be the material with the dominant impact on simulated BTC tailing. This influence results from the very low hydraulic conductivity of this material and its relatively large volume fraction, much larger than volume fraction at the SW site. For the source conditions used in the simulations, the dominant influence on transport at the site was retarded vertical diffusion, resulting in an extended period of "back diffusion" from these low conductive materials.

The simulated back diffusion from the silty clay material, for present setup, was expressed as extended periods of tailing after the original plume has passed through the sandy aquifer. This observation is consistent with field observations and numerical simulations that have identified low-conductive materials, either in the form of aquitard (Liu and Ball, 2002; Chapman and Parker, 2005), layers (Rasa et al., 2011) or distributed lenses (Parker et al., 2008), as the source of long tailing.

The simulations presented in this work suggest that BTC tailing, for conditions examined here, can be quantified by relatively simple bimodal heterogeneity models with diffusion in immobile zones (silty clay) and advection out (sands and gravel background). This is similar to findings of Chapman and Parker (2005) who found that TCE plume distribution in a sandy aquifer can be described by a model that simulates plume transport in aquifer combined with a back diffusion model from clayey silt aquitard. We show here that this finding is also valid for lens-shaped silty clay units, for present setup. 
A number of specific conclusions are offered for conditions similar to the parameter ranges considered in this manuscript:

- Two heterogeneity models (an inclusion-based model and a TP-based model), based on completely different mathematical models and numerical methodology but on same field data, produced very similar BTC tailing results when vertical characteristic scales of low conductive units were matched. The practical implication of this finding is that the accurate determination of the thickness (vertical characteristic scale) of the low conductive units is crucial to predicting tailing and back diffusion.

- The degree of simulated back diffusion was insensitive to the $K$ of these low conductive units and highly sensitive to the $K_{d}$ because of the impact of sorption on retarded diffusion. The insensitivity to $K$ (and dominance of diffusion) was explained using cutoff contrasts in $K$. The practical implications of these findings are twofold. First, accurate measurements of $\mathrm{K}$ of extremely low conductive units may not be required to simulate tailing and back diffusion provided sufficient contrast between the low $\mathrm{K}$ and adjoining more permeable materials. Second, accurate determination of $K_{d}$ for low- $K$ materials is required for robust modeling of contaminant tailing.

- The simulated BTC tailing was very sensitive to the vertical extent of the thin low conductive materials and longer tailing was generated by the thicker low conductive materials. This is consistent with findings of Parker et al. (2008) who found that back diffusion from a thick clay lens continues long after source removal and the completion of back diffusion from thin clay lenses. While an accurate estimation of the vertical extent of thin low conductive materials is highly important for model estimation, the 
estimation of their horizontal extent is less important. This was demonstrated by investigating sensitivity of tailing on horizontal scale of thin low conductive lenses.

- For the conditions of this work, the simulated BTC tailing was somewhat sensitive to volume fraction of thin low conductive units. The sensitivity depends on shape of these units. However, the impact of volume fractions on tailing was found to be smaller than the impact of shape (i.e. thickness of thin low conductive units).

- Finally, it was shown that the highly-sorbing sandy gravel material can cause delays in contaminant transport in low heterogeneous formations (e.g. SW site), for higher gravel volume fractions and for sorption distribution coefficient between 3 and $6 \mathrm{~mL} / \mathrm{g}$ investigated here.

\section{Acknowledgements}

Funding support for this work was provided by SERDP (Strategic Environmental Research and Development Program) under project number ER-1738. Views, opinions and/or findings contained in this report are those of the authors and should not be construed as an official Department of Defense position or decision unless so designated by other official documentation. Supercomputer simulations were run at Center for Computational Research, University at Buffalo that provided CPU time for our experiments.

\section{References}


Allen-King, R.M., Halket, R.M., Gaylord, D.R., Robin, M.J.L., 1998. Characterizing the heterogeneity and correlation of perchloroethene sorption and hydraulic conductivity using a facies approach. Water Resour. Res. 34(3), 385-396. doi:10.1029/97WR03496.

Allen-King, R.M., Divine, D.P., Robin, M.J.L., Alldredge, J.R., Gaylord, D.R., 2006. Spatial distributions of perchloroethylene reactive transport parameters in the Borden aquifer. Water Resour. Res. 42,W01413. doi:10.1029/2005WR003977.

Allen-King, R. M., I. Kalinovich, D. F. Dominic, G. Wang, R. Polmanteer, and D. Divine, 2015. Hydrophobic organic contaminant transport property heterogeneity in the Borden aquifer, Water Resour. Res. In press. doi: 10.1002/2014WR016161.

ASTM D5084-10 (2010), Standard Test Methods for Measurement of Hydraulic Conductivity of Saturated Porous Materials Using a Flexible Wall Permeameter, ASTM International, West Conshohocken, PA, www.astm.org, doi: 10.1520/D5084-10.

Bellin, A., Rinaldo, A., Bosma, W.J.P., Van der Zee, S.E.A.T.M., Rubin, Y., 1993. Linear equilibrium adsorbing solute transport in physically and chemically heterogeneous porous formations 1. Analytical solutions. Water Resour. Res. 29(12), 4019-4030.

Burr, D.T., Sudicky, E.A., Naff, R.L., 1994. Nonreactive and reactive solute transport in threedimensional heterogeneous porous media: Mean displacement, plume spreading, and uncertainty. Water Resour. Res. 30(3), 791-815. doi: 10.1029/93WR02946.

Carle, S.F., Fogg, G.E., 1996. Transition probability indicator geostatistics. Math. Geol. 28(4). $453-476$. 
Carle, S.F., Fogg, G.E., 1997. Modeling spatial variability with one and multidimensional continuous-lag Markov chains. Math. Geol. 29(7). 891-918.

Carle, S. F., 1999. T-PROGS: Transition Probability Geostatistical Software, Version 2.1. Univesity of California, Davis.

Chapman, S.W., Parker, B.L., 2005. Plume persistence due to aquitard back diffusion following dense nonaqueous phase liquid source removal or isolation. Water Resour. Res. 41.W12411. doi:10.1029/2005WR004224.

Cvetkovic, V.D., Shapiro, A.M., 1990. Mass arrival of sorptive solute in heterogeneous porous media. Water Resour. Res. 26(9). 2057-2067. doi:10.1029/WR026i009p02057.

Dagan, G., 1989. Flow and Transport in Porous Formations. Heidelberg: Springer-Verlag. 465p.

Dagan, G., Fiori, A., Jankovic, I., 2003. Flow and transport in highly heterogeneous formations: 1. Conceptual framework and validity of first-order approximations. Water Resour. Res. 39(9). 1268. doi:10.1029/2002WR001717.

Deng, H., Dai, Z., Wolfsberg, A.V., Ye, M., Stauffer, P.H., Lu, Z., Kwicklis, E., 2013. Upscaling retardation factor in hierarchical porous media with multimodal reactive mineral facies. Chemosphere 91(3). 248-257. doi:10.1016/j.chemosphere.2012.10.105.

Dentz, M., Castro, A., 2009. Effective transport dynamics in porous media with heterogeneous retardation properties. Geophys. Res. Lett. 36. L03403. doi:10.1029/2008GL036846.

Deutsch, C. V., and A. G. Journel (1997), GSLIB: Geostatistical Software Library and User's Guide, Edition 2, Oxford University Press, New York, 384 pp. 
Fernandez-Garcia, D., Illangasekare, T.H., Rajaram, H., 2004. Conservative and sorptive forcedgradient and uniform flow tracer tests in a three-dimensional laboratory test aquifer. Water Resour. Res. 40(10). W10103. doi:10.1029/2004WR003112.

Fernandez-Garcia, D., Illangasekare, T.H., Rajaram, H., 2005. Differences in the scale dependence of dispersivity and retardation factors estimated from forced-gradient and uniform flow tracer tests in three-dimensional physically and chemically heterogeneous porous media. Water Resour. Res. 41(3). W03012. doi:10.1029/2004WR003125.

Firmani, G., Fiori, A., Jankovic, I., Dagan, G., 2009. Effective conductivity of random multiphase 2D media with polydisperse circular inclusions. Multiscale Model. Simul. 7(4). 1979-2001.

Fiori, A., Jankovic, I., Dagan, G., 2005. Effective conductivity of heterogeneous multiphase media with circular inclusions. Phys. Rev. Lett. 94. 224502. doi:10.1103/PhysRevLett.94.224502.

Fiori, A., Jankovic, I., Dagan, G., 2006. Modeling flow and transport in highly heterogeneous three-dimensional aquifers: Ergodicity, Gaussianity, and anomalous behavior- 2 . Approximate semianalytical solution. Water Resour. Res. 42. W06D13. doi:10.1029/2005WR004752.

Fiori, A., Dagan, G., Jankovic, I., Zarlenga, A., 2013. The plume spreading in the MADE transport experiment: Could it be predicted by stochastic models?. Water Resour. Res. 49. 1-11. doi:10.1002/wrcr.20128. 
Foster-Reid, G.H., 1994. Variability of Hydraulic Conductivity and Sorption in a Heterogeneous Aquifer. MS thesis, Dep. of Civ. and Environ. Eng., Mass. Inst. of Technol., Mass.

Gelhar, L.W., 1993. Stochastic Subsurface Hydrology, Prentice-Hall, Old Tappan, N. J.

Grathwohl, P., 1998. Diffusion in natural porous media: contaminant transport, sorption/desorption and dissolution kinetics. Kluwer Academic Publishers. 207p.

Jankovic, I., Barnes, R., 1999, Three-dimensional flow through large numbers of spheroidal inhomogeneities. J. Hydrology 226. 224-233. doi: 10.1016/S0022-1694(99)00141-9.

Jankovic, I., Fiori, A., Dagan, G., 2003a, Effective conductivity of an isotropic heterogeneous medium of lognormal conductivity distribution. Multiscale Model. Simul. 1(1). 40-56. doi:10.1137/100805662.

Jankovic, I., Fiori, A., Dagan, G., 2003b. Flow and transport in highly heterogeneous formations: 3. Numerical simulations and comparison with theoretical results. Water Resour. Res. 39(9). 1270. doi:10.1029/2002WR001721.

Jankovic, I., Fiori, A., Dagan, G., 2006. Modeling flow and transport in highly heterogeneous three-dimensional aquifers: Ergodicity, Gaussianity, and anomalous behavior-1. Conceptual issues and numerical simulations. Water Resour. Res. 42. W06D12. doi:10.1029/2005WR004734.

Jankovic, I., Fiori, A., Dagan, G., 2009. The impact of local diffusion on longitudinal macrodispersivity and its major effect upon anomalous transport in highly heterogeneous aquifers. Adv. Water Resour. 32. 659-669. 
Jankovic, I., Fiori, A., 2009. Analysis of the impact of injection mode in transport through strongly heterogeneous aquifers, Adv. Water Resour., 33(10), 1199-1205, doi:10.1016/j.advwatres.2010.05.006.

Jankovic, I., Fiori, A., Dagan, G., 2013. Effective conductivity of isotropic highly heterogeneous formations: Numerical and theoretical issues. Water Resour. Res. 49. 1178-1183. doi: 10.1029/2012WR012441.

Levy, M., Berkowitz, B., 2003. Measurement and analysis of non-Fickian dispersion in heterogeneous porous media. J. Contam. Hydrol. 64. 203-226. doi:10.1016/S01697722(02)00204-8.

Liu, C., Ball, W.P., 2002. Back diffusion of chlorinated solvent contaminants from a natural aquitard to a remediated aquifer under well-controlled field conditions: Predictions and measurements. Ground Water 40(2). 175-184. doi:10.1111/j.1745-6584.2002.tb02502.x.

Mackay, D.M., Freyberg, D.L., Roberts, P.V., Cherry, J.A., 1986. A natural gradient experiment on solute transport in a sand aquifer: 1. Approach and overview of plume movement. Water Resour. Res. 22(13). 2017-2029. doi:10.1029/WR022i013p02017.

Maghrebi, M., Jankovic, I., Fiori, A., Dagan, G., 2013. Effective retardation factor for transport of reactive solutes in highly heterogeneous porous formations, Water Resour. Res. 49(12). 8600-8604. doi:10.1002/2013WR014429.

Maghrebi, M., Jankovic, I., Allen-King, R.M., Rabideau, A.J., Kalinovich, I., Wissmann, G.S., 2014. Impacts of transport mechanisms and plume history on tailing of sorbing plumes in 
heterogeneous porous formations, Adv. Water Resour. 73. 123-133.

doi:10.1016/j.advwatres.2014.07.007.

de Marsily, Gh., Delay, F., Goncalves, J., Renard, Ph., Teles, V., Violette, S., 2005. Dealing with spatial heterogeneity, Hydrogeol J 13. 161-183. doi: 10.1007/s10040-004-0432-3.

Meakin, P., Jullien, R., 1992. Random-sequential adsorption of disks of different sizes, Phys. Rev. A 46(4). 2029-2038. doi:10.1103/PhysRevA.46.2029.

National Research Council (NRC). 1994. Alternatives for Ground Water Cleanup. Washington, D.C.: The national academies press. 336p.

National Research Council (NRC). 2004. Contaminants in the Subsurface: Source Zone Assessment and Remediation. Washington, D.C.: The national academies press. 372p.

National Research Council (NRC). 2012. Alternatives for Managing the Nation's Complex Contaminated Groundwater Sites. Washington, D.C.: The national academies press. 240p.

Parker, B.L., Chapman, S.W., Guilbeault, M.A., 2008. Plume persistence caused by back diffusion from thin clay layers in a sand aquifer following TCE source-zone hydraulic isolation. J. Contam. Hydrol. 102. 86-104. doi:10.1016/j.jconhyd.2008.07.003.

Pollock, D.W., 1994. User's Guide for MODPATH/MODPATH-PLOT, Version 3: A particle tracking post-processing package for MODFLOW, the U.S. Geological Survey finitedifference ground-water flow model. U.S. Geological Survey, Open-File Report 94-464.

Rajaram, H., 1997. Time and scale dependent effective retardation factors in heterogeneous aquifers. Adv. Water Resour. 20(4). 217-230, doi:10.1016/S0309-1708(96)00021-8. 
Rasa, E., Chapman, S.W., Bekins, B.A., Fogg, G.E., Scow, K.M., Mackay, D.M., 2011. Role of back diffusion and biodegradation reactions in sustaining an MTBE/TBA plume in alluvial media. J. Contam. Hydrol. 126. 235-247. doi:10.1016/j.jconhyd.2011.08.006.

Robin, M.J.L., Sudicky, E.A., Gillham, R.W., Kachanoski, R.G., 1991. Spatial variability of Strontium distribution coefficients and their correlation with hydraulic conductivity in the Canadian Forces Base Borden Aquifer. Water Resour. Res. 27(10). 2619-2632. doi:10.1029/91WR01107.

Roberts, P.V., Goltz, M.N., Mackay, D.M., 1986. A natural gradient experiment on solute transport in a sand aquifer: 3. Retardation estimates and mass balances for organic solutes. Water Resour. Res. 22(13). 2047-2058. doi: 10.1029/WR022i013p02047.

Seyedabbasi, M.A., Newell, C.J., Adamson, D.T., Sale, T.C., 2012. Relative contribution of DNAPL dissolution and matrix diffusion to the long-term persistence of chlorinated solvent source zones. J. Contam. Hydrol. 134-135. 69-81. doi:10.1016/j.jconhyd.2012.03.010.

Silliman, S.E., Simpson, E.S., 1987. Laboratory evidence of the scale effect in dispersion of solutes in porous media. Water Resour. Res. 23(8). 1667-1673. doi:10.1029/WR023i008p01667.

Singh, A., Allen-King, R.M., Rabideau, A.J., 2014. Groundwater transport modeling with nonlinear sorption and intraparticle diffusion. Adv. Water Resour. 70. 12-23. doi: 10.1016/j.advwatres.2014.04.010.

Soltanian, M.R., Ritzi, R., Dai, Z., Huang, C., Dominic, D., 2014. Transport of kinetically sorbing solutes in heterogeneous sediments with multimodal conductivity and hierarchical 
organization across scales. Stoch Environ Res Risk Assess. doi:10.1007/s00477-014-09223.

Soltanian, M.R., Ritzi, R., Huang, C.C., Dai, Z., Deng, H., 2015. A note on upscaling retardation factor in hierarchical porous media with multimodal reactive mineral facies. Transp. Porous Med. 108. 355-366. doi: 10.1007/s11242-015-0480-2.

Sudicky, E.A., 1986. A natural gradient experiment on solute transport in a sand aquifer: Spatial variability of hydraulic conductivity and its role in the dispersion process. Water Resour. Res. 22(13). 2069-2082. doi:10.1029/WR022i013p02069.

Suribhatla, R., Jankovic, I., Fiori, A., Zarlenga, A., Dagan, G., 2011. Effective conductivity of an anisotropic heterogeneous medium of random conductivity distribution. Multiscale Model. Simul. 9(3). 933-954. doi:10.1137/100805662.

Tompson, A.F.B., Vomvoris, E.G., Gelhar, L.W., 1988. Numerical simulation of solute transport in randomly heterogeneous porous media: Motivation, model development, and application. Ralph M. Parsons Laboratory. Report number 316. Massachusetts Inst Technolg.

Tompson, A.F.B., Falgout, R.D., Smith, S.G., Bosl, W.J., Ashby, S.F., 1998. Analysis of subsurface contaminant migration and remediation using high performance computing, Adv. Water Resour. 22(3). 203-221. doi: 0.1016/S0309-1708(98)00013-X.

Wang, W., Wang, J., Kim, M., 2001. An algebraic condition for the separation of two ellipsoids. Comput. Aided Geom. Des. 18(6). 531-539. doi:10.1016/S0167-8396(01)00049-8. 
Weissmann, G.S., Pickel, L., McNamara, K.C., Frechette, J.D., Kalinovich, I., Allen-King, R.M., Jankovic, I., 2015. Characterization and quantification of aquifer heterogeneity using outcrop analogs at the Canadian Forces Base Borden, Ontario, Canada. GSA Bulletin. 31193. doi: 10.1130/B31193.1.

Woodbury, A. D., Sudicky, E. A. 1991. The geostatistical characteristics of the Borden aquifer, Water Resour. Res. 27(4). 533-546. doi: 10.1029/90WR02545.

Zinn, B., Harvey, C.F., 2003. When good statistical models of aquifer heterogeneity go bad: A comparison of flow, dispersion, and mass transfer in connected and multivariate Gaussian hydraulic conductivity fields, Water Resour. Res. 39(3). 1051. doi:10.1029/2001WR001146. 


\section{List of Tables:}

Table 1. The indicator geostatistics and material group properties at the site.

\begin{tabular}{|c|c|c|c|c|c|}
\hline \multirow{3}{*}{ Material Group } & \multicolumn{3}{|c|}{ Indicator Geostatistics } & \multirow{2}{*}{\multicolumn{2}{|c|}{ Representative Properties }} \\
\hline & \multirow[b]{2}{*}{ Volume Fraction (\%) } & \multicolumn{2}{|c|}{ Correlation Lengths (m) } & & \\
\hline & & Horizontal & Vertical & $\begin{array}{c}K(\mathrm{~cm} / \mathrm{s}) \\
* *\end{array}$ & $\begin{array}{c}\mathrm{PCE} K_{d * *}(\mathrm{~mL} / \mathrm{g}) \\
* * *\end{array}$ \\
\hline Sandy Gravel & 0.7 & $0.30^{*}$ & 0.05 & $5.93 \times 10^{-2}$ & 3.00 \\
\hline Lenticular Sands & 51.3 & 2.12 & $0.36^{*}$ & $1.69 \times 10^{-2}$ & 0.41 \\
\hline Tabular Sands & 24.6 & 2.34 & 0.15 & $1.97 \times 10^{-2}$ & 0.54 \\
\hline Silty Clay & 23.4 & 3.66 & $0.10^{*}$ & $6.37 \times 10^{-7}$ & 0.66 \\
\hline
\end{tabular}

${ }^{*}$ Questionable reliability, due to limited extent of a few outcrop panels (e.g. AL1 in vertical direction for silty clayFigure 2).

** $K$ of Sandy Gravel was obtained from Allen-King et al., (2015) - Sandy Gravel corresponds to "massive, medium grained" material; $K$ values of two sand units were obtained by self-consistent averaging (Dagan, 1989; Suribhatla et al., 2011) of $K$ of the equivalent lithofacies defined in Allen-King et al., (2015): Lenticular Sands is made of "medium, planar laminated, faint \& high-angle planar cross-stratified \& ripple produced cross-stratified to complexly cross-stratified" materials, while Tabular Sands is made of "massive, fine grained \& distinct, planar laminated \& faint, planar laminated" materials; Silty Clay $K$ was based on two measurements (as explained in Section 2.1 here)

***Estimated as the arithmetic average of $K_{d}$ of the equivalent lithofacies (from Allen-King et al., (2015)) and Silty Clay that corresponds to "Silt" of Allen-King et al., (2015)

Table 2. Indicator geostatistical parameters of model realizations.

\begin{tabular}{|c|c|c|c|c|c|c|c|c|}
\hline \multirow[b]{2}{*}{ Model/Field } & \multicolumn{2}{|c|}{ Sandy Gravel } & \multicolumn{2}{|c|}{ Lenticular Sands } & \multicolumn{2}{|c|}{ Tabular Sands } & \multicolumn{2}{|c|}{ Silty Clay } \\
\hline & $\begin{array}{l}\text { V.F. }{ }^{(1)} \\
(\%)\end{array}$ & $\begin{array}{l}\text { C.L. (2) } \\
\text { H/V (m) }\end{array}$ & $\begin{array}{l}\text { V.F. }{ }^{(1)} \\
(\%)\end{array}$ & $\begin{array}{l}\text { C.L. }{ }^{(2)} \\
\text { H/V (m) }\end{array}$ & $\begin{array}{l}\text { V.F. }{ }^{(1)} \\
(\%)\end{array}$ & $\begin{array}{l}\text { C.L. }{ }^{(2)} \\
\text { H/V (m) }\end{array}$ & $\begin{array}{l}\text { V.F. }{ }^{(1)} \\
(\%)\end{array}$ & $\begin{array}{l}\text { C.L. }{ }^{(2)} \\
\text { H/V (m) }\end{array}$ \\
\hline Inclusions Model & 0.3 & $0.20 / 0.06$ & 22.0 & $2.04 / 0.34$ & 10.6 & $2.42 / 0.15$ & 10.1 & $3.72 / 0.09$ \\
\hline Silty Clay-Only Inclusions Model & - & - & - & - & - & - & 23.4 & $3.14 / 0.08$ \\
\hline TP-based Model & 0.3 & $0.12 / 0.02$ & 50.3 & $2.54 / 0.17$ & 24.8 & $1.80 / 0.09$ & 24.6 & $2.74 / 0.17$ \\
\hline $\begin{array}{l}\text { Borden Field Data } \\
\quad(\text { Section } 2.1)\end{array}$ & 0.7 & $0.30 / 0.05$ & 51.3 & $2.12 / 0.36$ & 24.6 & $2.34 / 0.15$ & 23.4 & $3.66 / 0.10$ \\
\hline
\end{tabular}

(1) V.F. = Volume Fraction

(2) C.L. = Correlation Lengths

Table 3. Overall $\ln K(\boldsymbol{x})$ and $\ln K_{d}(\boldsymbol{x})$ geostatistics of model realizations ( $K$ in $\mathrm{cm} / \mathrm{s}$ and $K_{d}$ in $\mathrm{mL} / \mathrm{g})$.

\begin{tabular}{|c|c|c|c|c|c|c|}
\hline \multirow{2}{*}{ Model/Field } & \multicolumn{3}{|c|}{$\ln K(\mathbf{x})$ Field } & \multicolumn{3}{c|}{$\ln K d(\mathbf{x})$ Field } \\
\cline { 2 - 7 } & Mean & Variance & $\begin{array}{c}\text { Correlation lengths } \\
I_{h M} / I_{v M}(\mathrm{~m})\end{array}$ & Mean & $\begin{array}{c}\text { Variance } \\
\text { Correlation lengths } \\
\mathrm{H} / \mathrm{V}(\mathrm{m})\end{array}$ \\
\hline Inclusions Model & -5.17 & 8.5 & $3.75 / 0.10$ & -0.62 & 0.01 & $0.87 / 0.06$ \\
\hline Silty Clay-Only Inclusions Model & -6.15 & 17.5 & $3.14 / 0.08$ & -0.67 & 0.02 & $3.09 / 0.08$ \\
\hline
\end{tabular}




\begin{tabular}{|c|c|c|c|c|c|c|}
\hline TP-based Model & -6.54 & 19.5 & $2.71 / 0.17$ & -0.70 & 0.05 & $1.87 / 0.16$ \\
\hline $\begin{array}{c}\text { Borden Field Data } \\
\text { (Section 2.1) }\end{array}$ & -6.40 & 18.9 & $1.95 / 0.09\left(I_{h} / I_{v}\right)$ & -0.70 & 0.06 & $2.30 / 0.10$ \\
\hline
\end{tabular}

\section{List of Figures:}

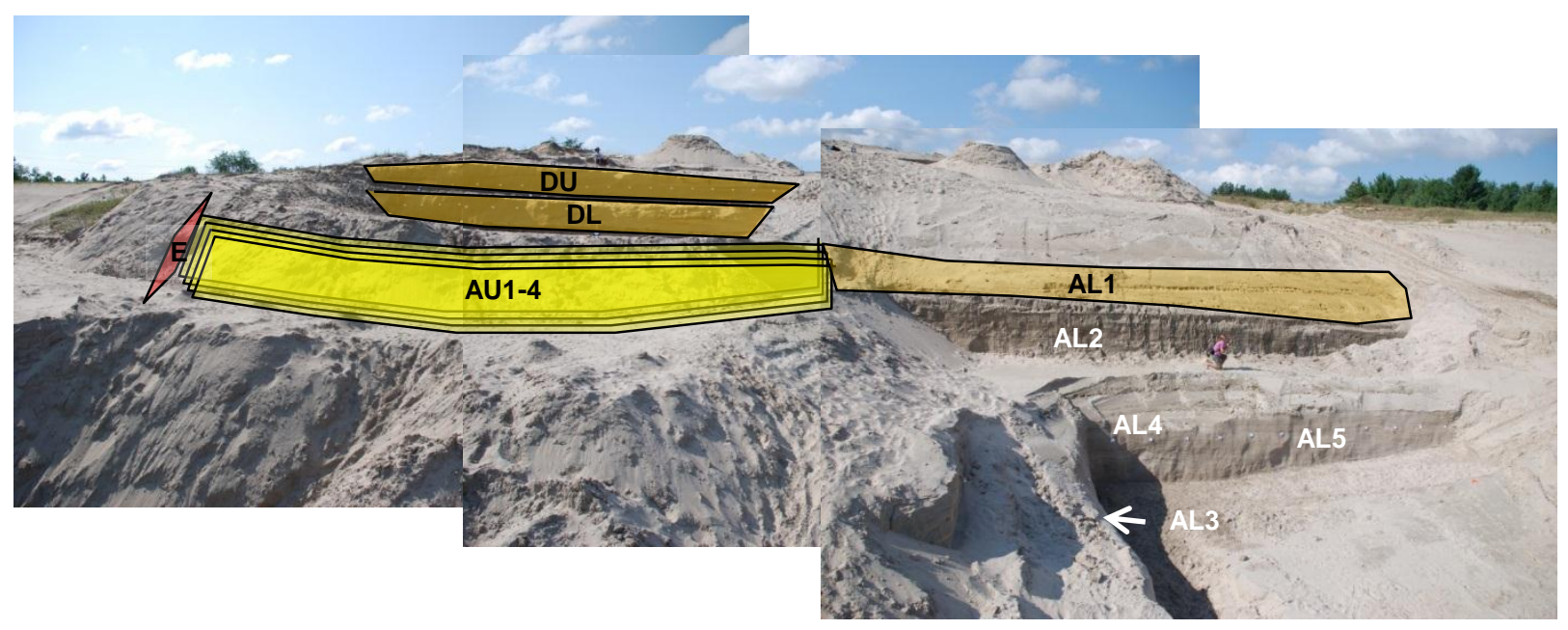

Fig. 1. Site photograph with outcrop panels exposed by an excavator in several stages. 

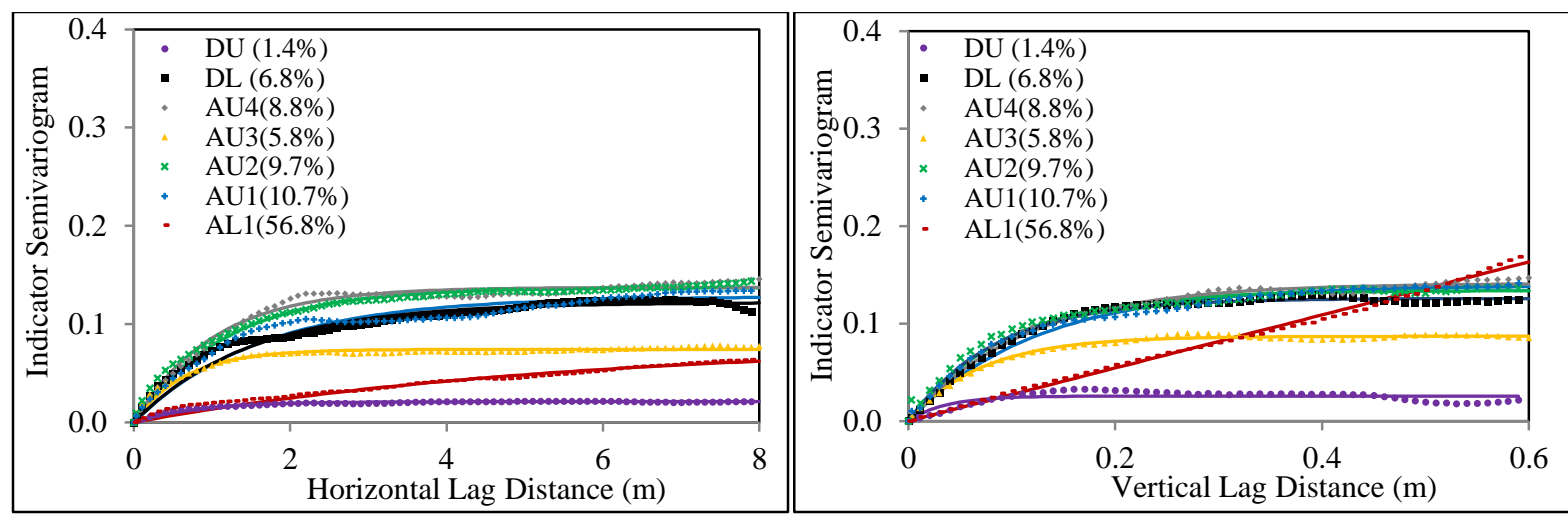

Fig. 2. An example of experimental indicator semivariograms (dots) for silty clay in each outcrop panels in horizontal direction (left) and vertical direction (right) with distribution (in percentages) of the silty clay over outcrop panels.

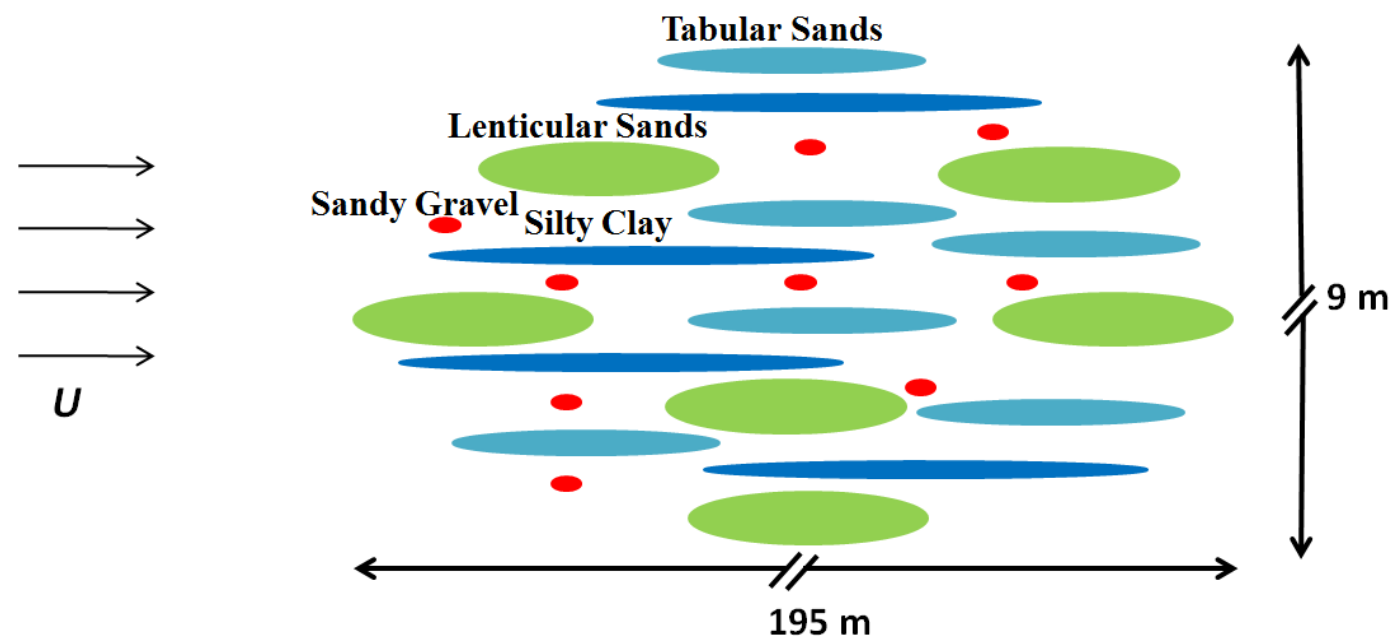

Fig. 3. Schematic of the inclusions model; the sandy gravel, lenticular sands, tabular sands, and silty clay material groups are represented by red, green, light blue, and dark blue inclusions, respectively. 


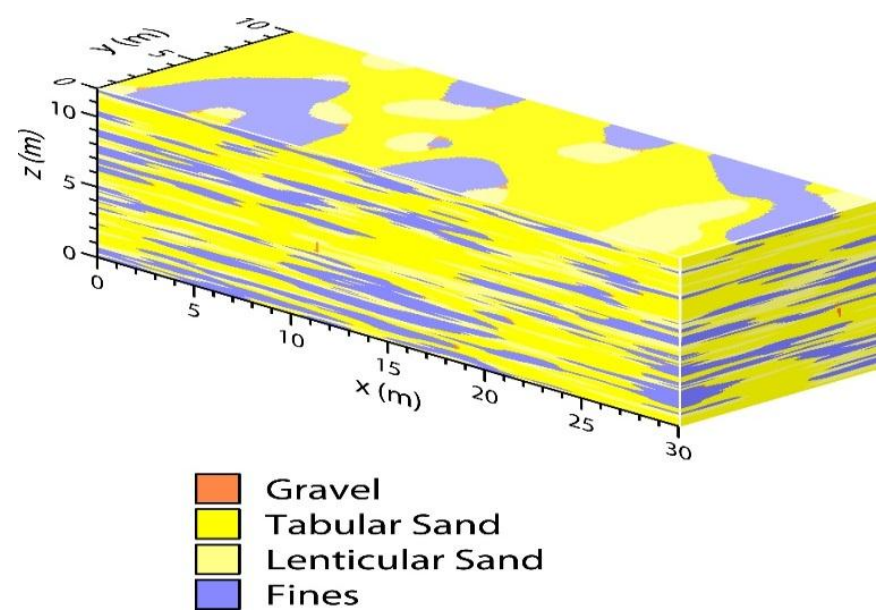

Fig. 4. 3D representation of TP-based model with silty clay material referred to as "Fines"
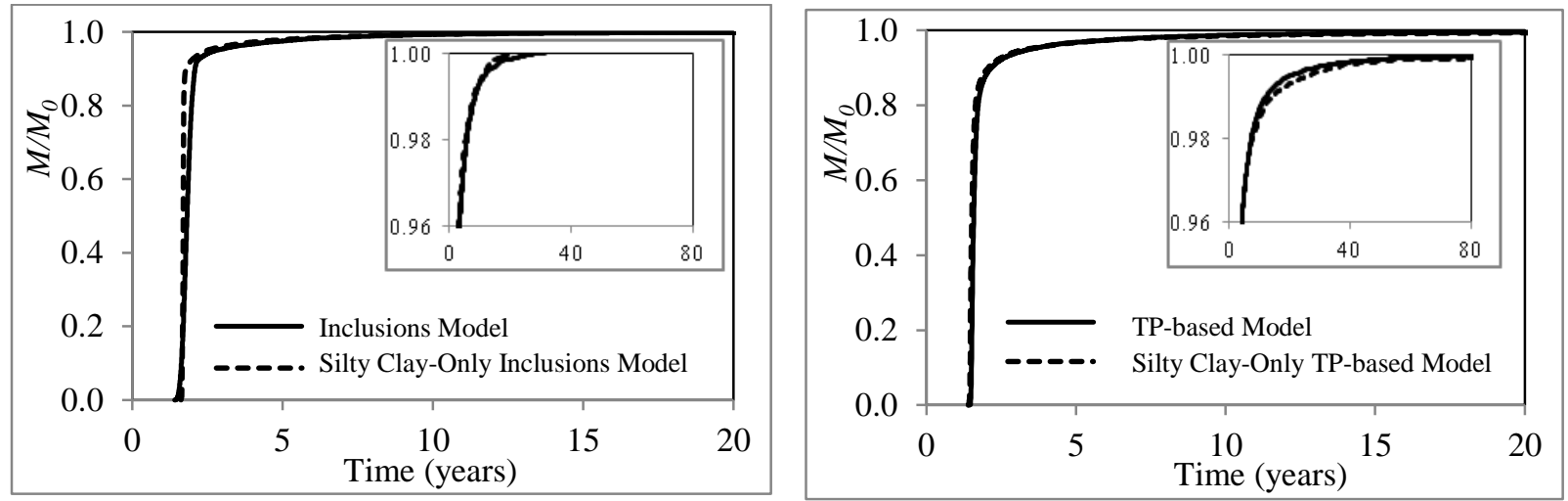

Fig. 5. Comparison of BTCs for inclusions model (left) and TP-based model (right) with their silty clay- only equivalents for control plane $19.5 \mathrm{~m}$ from the injection plane (inclusions model) and $20 \mathrm{~m}$ from the injection plane (TP-based model). 

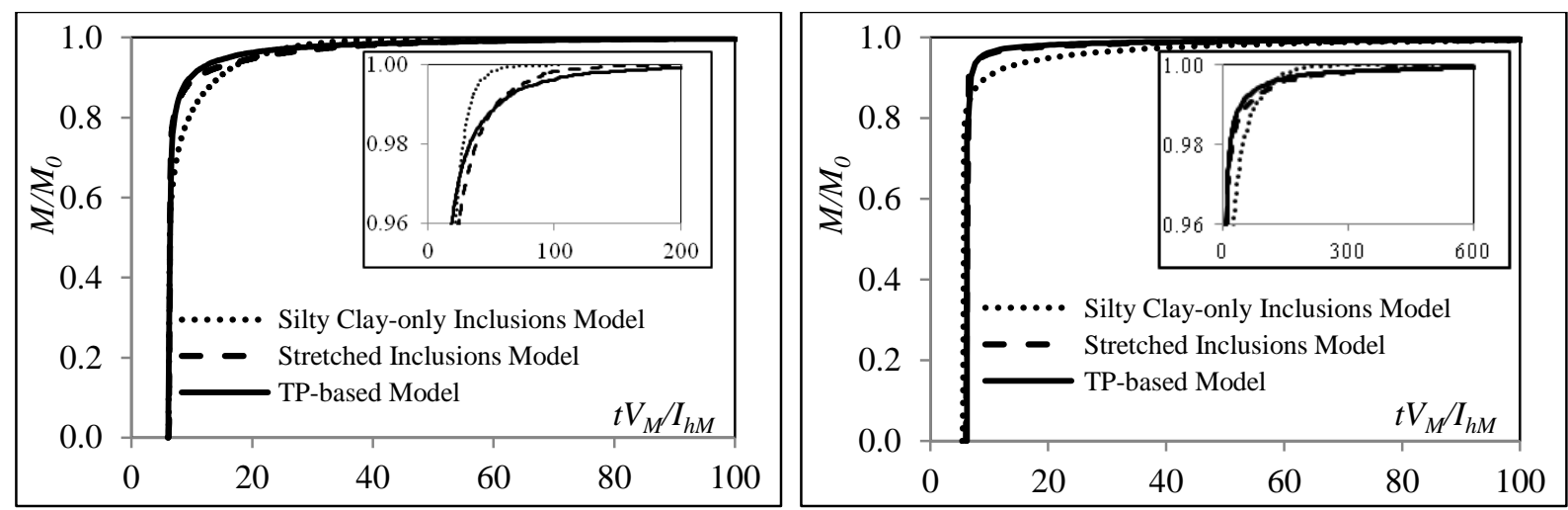

Fig. 6. Comparison of BTCs of silty clay-only inclusions model and TP-based model for $P e=10^{4}$ (left) and $P e=10^{5}$ (right) for control plane $8.8 I_{h M}$ downstream of the injection plane.
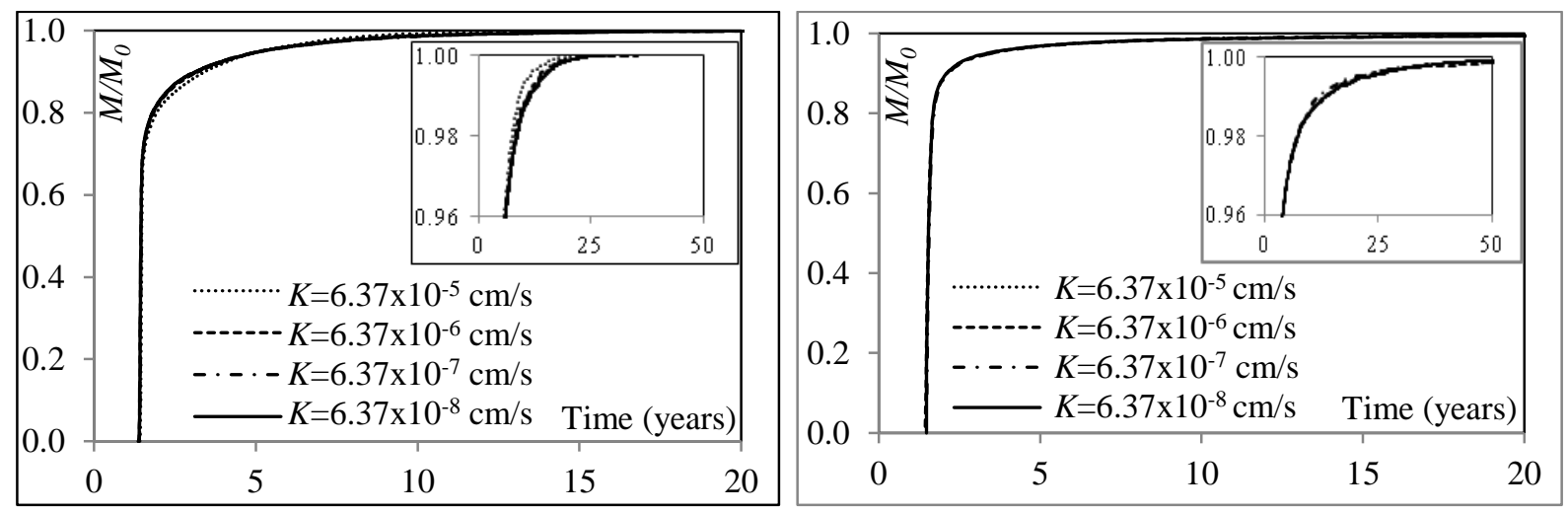

Fig. 7. Sensitivity of transport results for the silty clay-only inclusions model for a control plane at $19.5 \mathrm{~m}$ from the injection plane (left) and TP-based model for a control plane at $20 \mathrm{~m}$ from the injection plane (right) on $K$ of silty clay material. 

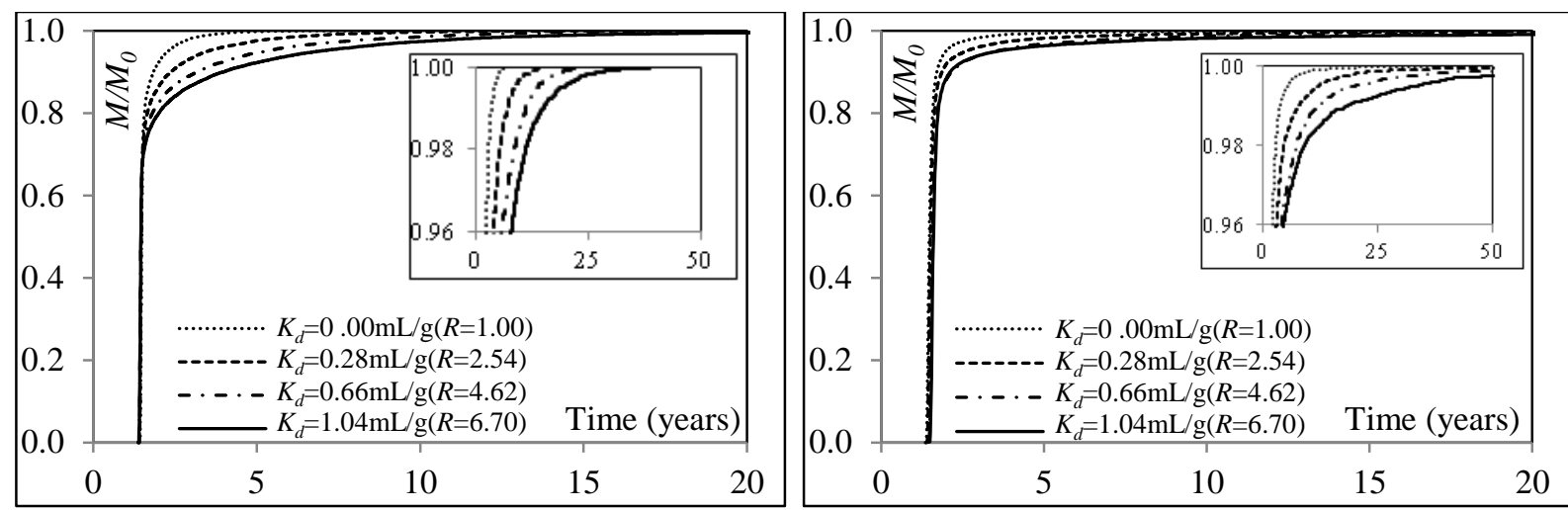

Fig. 8. Sensitivity of transport results for the silty clay-only inclusions model (left) and TP-based model (right) to $K_{d}$ of silty clay material.
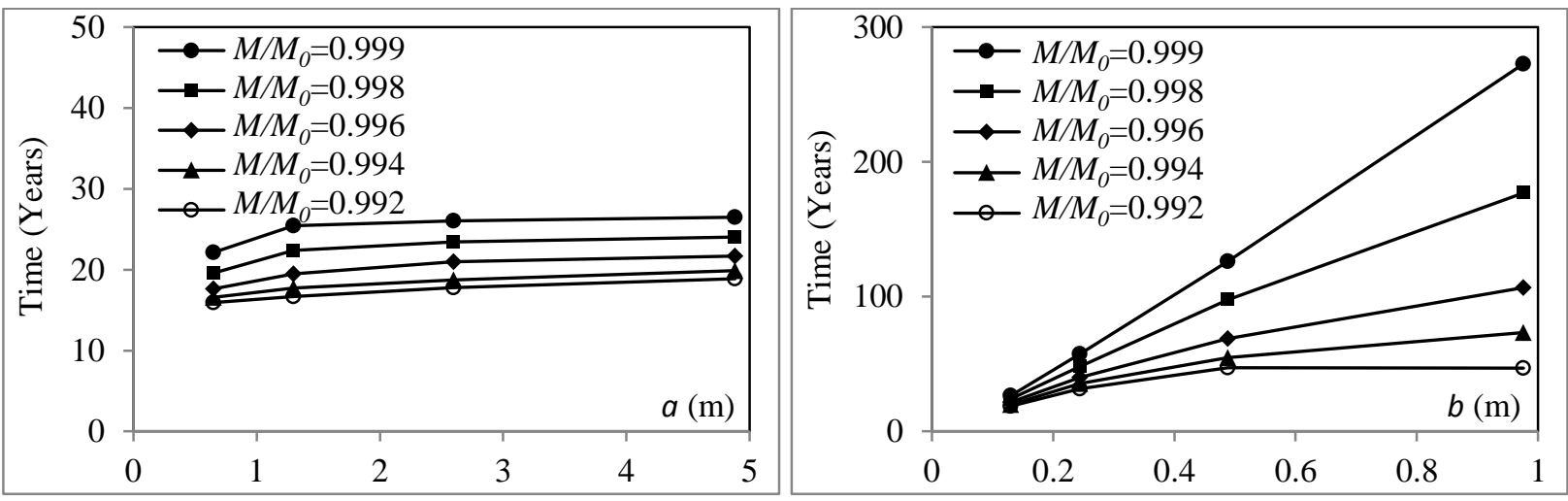

Fig. 9. Sensitivity of tailing to horizontal semi-axis ( $a$ ) for fixed $b=0.13 \mathrm{~m}$ (left) and vertical semi-axis ( $b$ ) for fixed $a=4.88 \mathrm{~m}$ (right) of the silty clay inclusions in the silty clay-only inclusions model for $P e=10^{4}$ at control plane $48.75 \mathrm{~m}$ from the injection plane. 

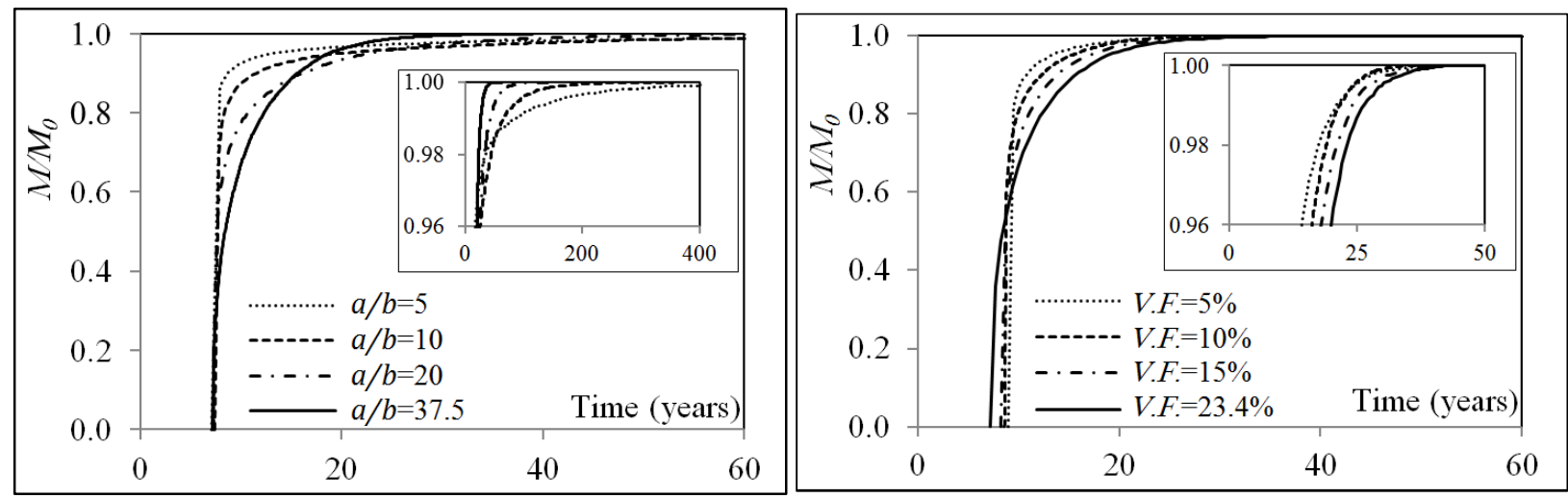

Fig. 10. Sensitivity of transport results for silty clay-only inclusions model to shape ratio $a / b$ for fixed volume fraction V.F. of $23.4 \%$ (left) and to the volume fraction V.F. of the silty clay inclusions for fixed $a / b=37.5$ (right).

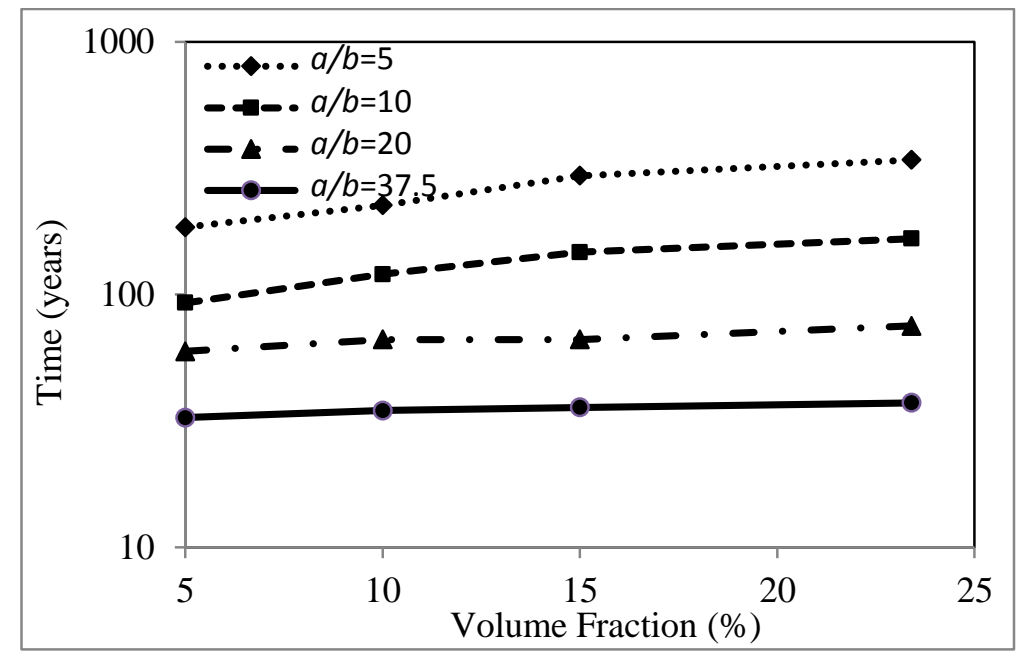

Fig. 11. Travel times that corresponds to $M / M_{0}=0.999$ for the silty clay-only inclusions model for varying volume fraction and the shape ratio $a / b$ of silty clay inclusions. 

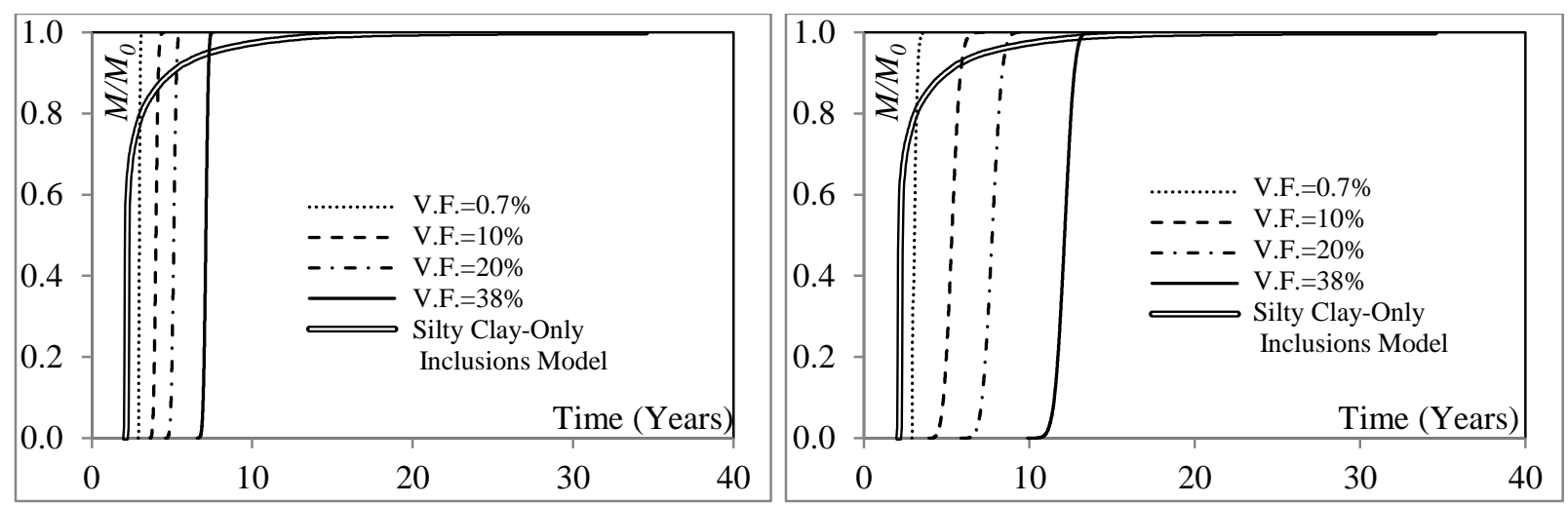

Fig. 12. The BTCs for sandy gravel-only inclusion model with different volume fractions (V.F.) of gravel inclusions with $K_{d}=3 \mathrm{~mL} / \mathrm{g}$ (left) and $K_{d}=6 \mathrm{~mL} / \mathrm{g}$ (right). The BTC of the silty clay-only inclusions model is presented for comparison. 